\title{
In the prevery
}

Welcome to the April 2010 issue of CERL News. Today's academic and research librarians are more intimately involved in the scholarly research process than ever before. Libraries now host of institutional repositories and serve as journal publishers. And librarians conduct the same sorts of qualitative and quantitative research that were once the purview of other academic departments.

With this shift in role comes a need to be fully versed in institutional policies, procedures, and standards for research. In this issue, Robert V. Labaree sheds light on the often mysterious processes of "Working with your institutional review board," a necessity when conducting any sort of research with human subjects.

In addition to creating original research, many libraries are changing the way data is stored and preserved in the Internet era. Sayeed Choudury discusses "Data curation" advances at Johns Hopkins and outlines ways that libraries can collaborate to create a data ecosystem.

Drawing new talent to the profession is critical to continuing the advancing climate of today's libraries. Dwight King outlines how Notre Dame partners with local high schools to recruit "The next generation" of minority librarians to the field. Recent MLIS graduates Rachel Cannady and Daniel Newton look to their own experiences to provide advice to help the new generation land their first jobs in their article "Making the best of the worst of times."

Make sure to take a look at all of the other great articles and columns, including a discussion of embedding library resources into courseware using LibGuides, Internet Resources on "Victorian literature and culture," and part two of our recognition of the 2010 ACRL award winners.

-David Free, editor-in-chief dfree@ala.org

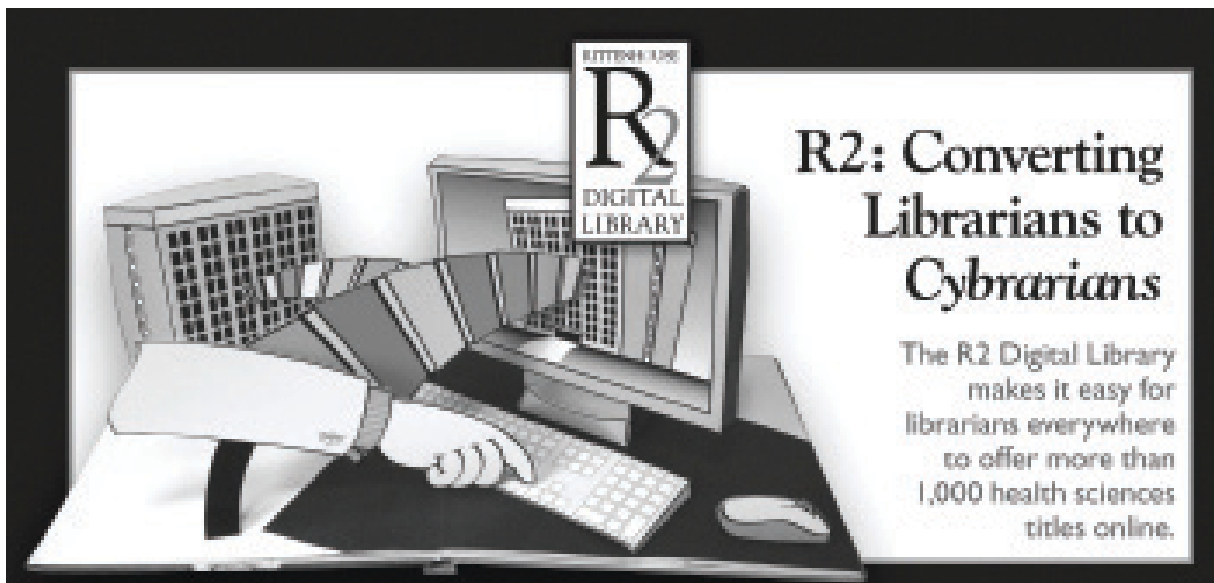

SAVE MONEY.

Avoid "all-or-nothing" prices. Add more titles immedlately with the push of a button.

SAVE TIME.

Easy-to-use interface. If you can surf the web, you can use R2.

MANAGE SMARTLY.

Menitor usage statistic in real time, so you can make informed decisions.

Rittenhouse

BDOK DISTEIBUTORS
5II Feheley Dr, King of Prussia, PA 19406 - 800-345-6425 www.2librarycom + www.rittenhouse.com 